2. Holm C, Mayr M, Höfter E, Ninkovic $M$. Perfusion zones of the DIEP flap revisited: a clinical study. Plast Reconstr Surg. 2006;117(1):37-43. doi:10.1097/01.prs.0000185867.84172.c0

3. Ireton JE, Lakhiani C, Saint-Cyr M. Vascular anatomy of the deep inferior epigastric artery perforator flap: a systematic review. Plast Reconstr Surg. 2014;134(5): 810e-821e. doi:10.1097/ PRS.0000000000000625

4. Grover R, Nelson JA, Fischer JP, Kovach SJ, Serletti JM, Wu LC. The impact of perforator number on deep inferior epigastric perforator flap breast reconstruction. Arch Plast Surg. 2014;41(1):63-70. doi:10.5999/aps.2014.41.1.63

5. Ulusal BG, Cheng M-H, Wei F-C, Ho-Asjoe M, Song $\mathbf{D}$. Breast reconstruction using the entire transverse abdominal adipocutaneous flap based on unilateral superficial or deep inferior epigastric vessels. Plast Reconstr Surg. 2006;117(5):13951403; discussion 1404-1406. doi:10.1097/ 01.prs.0000207401.78491.43

6. Deurenberg $P$, Deurenberg-Yap M, Guricci S. Asians are different from Caucasians and from each other in their body mass index/body fat per cent relationship. Obes Rev Off J Int Assoc Study Obes. 2002;3(3):141-146. doi:10.1046/j.1467789x.2002.00065.X

7. Myung $\mathbf{Y}$, Son $\mathbf{Y}, \operatorname{Nam} \mathbf{T}$, et al. Objective assessment of flap volume changes and aesthetic results after adjuvant radiation therapy in patients undergoing immediate autologous breast reconstruction. PLOS ONE. 2018;13(5):e0197615. doi:10.1371/journal.pone.0197615

8. Wilting $\mathbf{F N H}$, Hameeteman $\mathbf{M}$, Tielemans HJP, Ulrich DJO, Hummelink S. "Threedimensional evaluation of breast volume changes following autologous free flap breast reconstruction over six months." Breast Off ] Eur Soc Mastology. 2020;50:85-94. doi:10.1016/ j.breast.2020.02.005

\title{
KẾT QUẢ PHẪU THUÂTT NộI SOI SAU PHÚC MẠC CẮT NANG THẬN TẠI BỆNH VIỆN BẠCH MAI
}

\author{
Lorn Sopheak $^{1}$, Nguyễn Minh Tuấn ${ }^{2}$, Trần Hiếu Học ${ }^{1,2}$ \\ Trần Mạnh Hùng ${ }^{2}$, Nguyễn Trường Giang ${ }^{2}$

\section{RESULTS OF RETROPERITONEOSCOPIC SURGERY OF SIMPLE RENAL CYST AT BACH MAI HOSPITAL}

\section{TÓM TẮT}

Mục tiêu: Mô tả một số đặc điểm lâm sàng, cận lâm săng và đánh giá kết quả phẫu thuật nội soi sau phúc mạc cắt nang thận. Đối tượng và phương pháp: mô tả hồi cứu các bệnh nhân được chẩn đoán xác định và mổ nội soi sau phúc mạc cắt nang thận tại Bênh viên Bach Mai từ 01/2020 đến 06/ 2021. Kểt quả: 46 bệnh nhân với tuổi trung bình là $57,72 \pm$ $14,84(19-83)$, tỉ lệ nữ/nam là $1 / 1$. Đau thắt lưng là triệu chứng chính gặp ở $87 \%$. Thăm dò hình ảnh thấy đường kính nang, tỷ lê nhóm nang có kích thước 50$100 \mathrm{~mm}$ và thành mỏng trên chụp lớp ví tính và siêu âm lần lượt là $77,48 \pm 26,53 \mathrm{~mm}(45-183 \mathrm{~mm})$ và $79,17 \pm 26,05 \mathrm{~mm} \quad(45-183 \mathrm{~mm}), 76,1 \%$ và $78,3 \%$, $91,3 \%$ và $93,5 \%$. Thời phẫu thuâtt trung bình là $54,74 \pm 16,6$ phút. Tai biến: 1 trường hợp chảy máu $2,2 \%$. Biến chứng sau mổ: 2 bệnh nhân chảy máu qua dấn lưu 4,3\%. Thời gian nằm viện là $3,22 \pm 1,01$ ngày (2-6). Kết luân: Nôi soi sau phúc mạc cắt nang thận là phương pháp phẫu thuật an toàn và hiệu quả trong điều tri nang thân.

Tư khoá: Nang thận, cắt nang thận, phẫu thuật nội soi sau phúc mạc.

\section{SUMMARY}

${ }^{1}$ Trường Đại học Y Hà Nội

${ }^{2}$ Bênhh viện Bạch Mai

Chịu trách nhiệm chính: Lorn Sopheak.

Email: Iorn.sopheak@gmail.com

Ngày nhận bài: 13/7/2021

Ngày phản biên khoa hoc: 15/8/2021

Ngày duyệt bài: 30/8/2021
Objective: Description of some clinical, paraclinical characteristics and evaluation of the results of retroperitoneoscopic renal cystectomy. Subjects and methods: Retrospective description of the cases diagnosed simple renal cyst and underwent retroperitoneoscopic simple renal cystectomy at Bach Mai Hospital from January/2020 to June/2021. Results: There were 46 patients who underwent retroperitoneoscopic simple renal cystectomy with an average age of $57.72 \pm 14.84$ years old (range from 19 to 83 years). Ratio of male/female were $1 / 1$. The flank or back pain were the most common sign which happened in $87 \%$ patients. The average diameter in CT scaner of cyst was $77.48 \pm 26.53 \mathrm{~mm}(45-183 \mathrm{~mm})$, the size of $50-100 \mathrm{~mm}$ and thin cyst wall were $76.1 \%$ and $91.3 \%$, respectively. The average diameter in Echography of cyst was $79.17 \pm 26.05 \mathrm{~mm}$ (45-183mm), the size of $50-100 \mathrm{~mm}$ and thin cyst wall were $76.1 \%$ and $91.3 \%$, respectively. The operative time was $54.74 \pm 16.6$ minutes. The perioperative accident of bleeding was $2.2 \%$. The complications were postoperative bleeding $4.3 \%$. Median length of hospital stay was $3.22 \pm 1.01$ days (2-6). Conclusion: The retroperitoneoscopic cystectomy is a safe and effective procedure in the treatment of renal cysts with the low morbidity and excellent result.

Keyword: Kidney cysts, renal cystectomy, Retroperitoneoscopic surgery.

\section{I. ĐĂT VẤN ĐỀ}

Nang thận là tổn thương dạng nang lành tính 
hình thành từ nhu mô thân, chỉ ở mọt thùy thân, không thông với đài bể thận. Giả thuyết bẩm sinh được Kampmeier mô tả lần đầu 1923, giả thuyết mắc phải được Feiner đưa ra năm 1981. Bệnh hay gặp ở người lớn, ít gặp ở trẻ nhỏ và tỷ lệ mắc tăng theo tuổi. Nang thận ít khi biểu hiện triệu chứng, bệnh nhân thường đến viện vì những dấu hiệu không đặc hiệu: đau thắt lưng, đái máu, tăng huyết áp, nhiếm khuẩn tiết niệu. Bệnh có thể gây các biến chứng như: chèn ép hệ thống đài bể thận, võ̃ tự phát hoặc võ̃ do chấn thương và chảy máu trong nang [1]. Chẩn đoán xác định dựa vào siêu âm (SA) và chụp cắt lớp vi tính (CLVT). Việc điều trị chỉ đặt ra khi nang thận có biểu hiện triệu chứng hoặc khi phát hiện nang có kịch thước lớn. Hiện nay có nhiều phương pháp điều trị nang thận, trong đó phẫu thuật nội soi đặc biệt là nội soi sau phúc mạc cắt chỏm nang thận ngày càng trở nên phổ biến [2]. Bệnh viện Bạch Mai cũng đã triển khai phẫu thuật nội soi cắt nang thận từ năm 2005. Năm 2017 có một nghiên cứu về cắt chỏm nang bằng hai phương pháp phẫu thuật trong phúc mạc và sau phúc mạc [3]. Để đánh giá hiệu quả của riêng phẫu thuật nội soi sau phúc mạc trong điều trị nang thận rõ hơn chúng tôi tiến hành nghiên cứu đề tài này với mục đích: Mô tả một số đặc điểm lâm sàng, cận lâm sàng và đánh giá kết quả phẫu thuật nội soi sau phúc mạc cắt nang thận.

\section{II. ĐỐI TƯỢNG VÀ PHƯƠNG PHÁP NGHIÊN CỨU 2.1. Đối tượng nghiên cứu}

2.1.1. Tiêu chuẩn chọn bệnh nhân

\section{KẾT QUẢ NGHIÊN CỨU}

\subsection{Tuổi, giới tính}

Bảng 3.1. Phân bố nhóm bệnh nhân nghiên cứu theo tuổi, giới

\begin{tabular}{|c|c|c|c|c|c|c|}
\hline \multirow{2}{*}{ Nhóm tuối } & \multicolumn{2}{|c|}{ Nam } & \multicolumn{2}{c|}{ Nữ } & \multicolumn{2}{c|}{ Tống } \\
\cline { 2 - 7 } & $\mathbf{n}$ & $\mathbf{\%}$ & $\mathbf{n}$ & $\mathbf{\%}$ & $\mathbf{n}$ & $\mathbf{\%}$ \\
\hline$<20$ & 1 & 2,17 & 0 & 0 & 1 & 2,17 \\
\hline $20-29$ & 1 & 2,17 & 1 & 2,17 & 2 & 4,34 \\
\hline $30-39$ & 1 & 2,17 & 2 & 4,35 & 3 & 6,52 \\
\hline $40-49$ & 3 & 6,52 & 2 & 4,35 & 5 & 10,87 \\
\hline $50-59$ & 2 & 4,35 & 8 & 17,39 & 10 & 21,74 \\
\hline$\geq 60$ & 15 & 32,61 & 10 & 21,74 & 25 & 54,35 \\
\hline Tống & $\mathbf{2 3}$ & $\mathbf{5 0 \%}$ & $\mathbf{2 3}$ & $\mathbf{5 0 \%}$ & $\mathbf{4 6}$ & $\mathbf{1 0 0 \%}$ \\
\hline
\end{tabular}

Nhận xét: Tuối trung bình là $57,72 \pm 14,84$ tuối, cao nhất là 83 và thấp nhất là 19 tuối, độ tuối trên 50 tuổi chiếm $76.09 \%$. Tỉ lệ nữ/nam: 1/1.

3.2. Lâm sàng

Bảng 3.2. Triệu chứng lâm sàng và tiền sử của bênh nhân

\begin{tabular}{|c|c|c|}
\hline Triệu chứng & $\begin{array}{c}\text { Số beệnh } \\
\text { nhẩn }\end{array}$ & $\begin{array}{c}\text { Tế lệ } \\
\text { \% }\end{array}$ \\
\hline Đau thắt lưng & 36 & 78,3 \\
\hline
\end{tabular}

- Kích thước nang trên chụp cắt lớp vi tính và hơn $5 \mathrm{~cm}$ nhưng có triệu chứng lâm sàng hoặc có chèn ép đài bể thận.

- Đặc điểm nang trên chẩn đoán hình ảnh: nhóm I, II, theo Bosniak, nang ngoại vi.

\subsubsection{Tiêu chuẩn loại trừ}

Nang $<5 \mathrm{~cm}$ không có triệu chứng lâm sàng. Bệnh nhân có chống chỉ định gây mê nội khî quản hoặc chống chỉ định của phẩu thuật nội sau phúc mạc

\subsection{Phương pháp nghiên cứu}

- Thiết kế nghiên cứu: Nghiên cứu mô tả hồi cứu

- Địa điểm, thời gian nghiên cứu: Khoa Ngoại Tổng hợp bệnh viện Bạch Mai từ tháng 01 năm 2020 đến tháng 06 năm 2021

- Biến số nghiên cứu:

Gồm: Tuổi, giới, các triệu chứng lâm sàng (đau thắt lưng, tăng huyết áp, đái buốt đái dắt, đái máu hoặc phát hiện tình cờ, các bênh lý phối hợp), về cận lâm sàng (kích thước nang, độ dày thành nang trên chụp $C L V T$, trên $S A$ ), và kết quả điều trị (thời gian phẫu thuật, tai biến trong mổ, biến chứng sau mổ).

- Cỡ mẫu: Chọn mẫu thuận tiện

2.3. Phân tích và xử iý số liệu: Số liệu được thu thập và xử lý với phần mềm SPSS 22.0

2.4. Đạo đức nghiên cứu: Nghiên cứu hồi cứu, không can thiệp vào bệnh nhân. Các thông tin liên quan đến đối tượng nghiên cứu được giữ bí mật. trên siêu âm lớn hơn 50mm hoăc nang thận nhỏ

\begin{tabular}{|c|c|c|}
\hline $\begin{array}{c}\text { Đau thắt lưng + tăng } \\
\text { huyết áp }\end{array}$ & 2 & 4,3 \\
\hline $\begin{array}{c}\text { Đau thắt lưng + chạm } \\
\text { thận (+) }\end{array}$ & 2 & 4,3 \\
\hline $\begin{array}{c}\text { Phát hiện khi khám sức } \\
\text { khoẻ định kỳ }\end{array}$ & 6 & 13 \\
\hline
\end{tabular}




\begin{tabular}{|c|c|c|}
\hline Tống & $\mathbf{4 6}$ & $\mathbf{1 0 0}$ \\
\hline Bệnh kèm theo & $\begin{array}{c}\text { Số bệnh } \\
\text { nhấn }\end{array}$ & $\begin{array}{c}\text { Tế lệ } \\
\text { \%o }\end{array}$ \\
\hline Sỏi tiết niệu & 7 & 15,2 \\
\hline Nang gan & 3 & 6,5 \\
\hline Đái tháo đường & 5 & 10,9 \\
\hline Tăng huyết áp & 3 & 6,5 \\
\hline
\end{tabular}

Nhật xét: Đau thắt lưng là triêu chứng thường gặp nhất khi bệnh nhân vào viện (87\%). Một số ít có bệnh lý kèm theo như sỏi tiết niệu, nang gan, đái tháo đường và tăng huyết áp.

\subsection{Cận lâm sàng:}

Bảng 3.3. Kết quả của siêu âm, chụp cắt lớp vi tính và phân loại nang

\begin{tabular}{|c|c|c|c|c|}
\hline & $\begin{array}{c}\text { Siêu } \\
\text { âm } \\
\text { n (\%) }\end{array}$ & $\begin{array}{l}\text { CLVT } \\
\text { n (\%) }\end{array}$ & $\mathbf{P}$ \\
\hline \multirow[b]{2}{*}{$\begin{array}{l}\text { Đường kính } \\
(\mathrm{mm})\end{array}$} & $<50$ & $3(6,5)$ & $5(10,9)$ & \multirow[b]{2}{*}{$\begin{array}{c}0,40 \\
5\end{array}$} \\
\hline & \begin{tabular}{|c|}
$50-$ \\
100 \\
$>100$ \\
\end{tabular} & $\begin{array}{c}36 \\
(78,3) \\
7(15,2)\end{array}$ & $\begin{array}{c}35 \\
(76,1) \\
6(13,0)\end{array}$ & \\
\hline \multirow{2}{*}{$\begin{array}{l}\text { Độ dày } \\
\text { thành nang }\end{array}$} & Mỏng & $\begin{array}{c}43 \\
(93,5)\end{array}$ & $\begin{array}{c}42 \\
(91,3)\end{array}$ & \multirow{2}{*}{$\begin{array}{c}0,32 \\
3\end{array}$} \\
\hline & \begin{tabular}{|l|} 
Dày \\
\end{tabular} & $3(6,5)$ & $4(8,7)$ & \\
\hline \multicolumn{2}{|c|}{$\begin{array}{l}\text { Đường kính } \\
\text { trung bình }\end{array}$} & $\begin{array}{c}79,17 \pm \\
26,05\end{array}$ & $\begin{array}{c}77,48 \pm \\
26,53\end{array}$ & $\begin{array}{c}0,39 \\
9\end{array}$ \\
\hline $\begin{array}{c}\text { Phân loại } \\
\text { Bosniaḱ }\end{array}$ & $\frac{\text { I }}{\text { II }}$ & $40(8$ & $37 \%)$ & \\
\hline
\end{tabular}

Nhận xét: Không có khác nhau có ý nghĩa về đă điểm kích thước, đường kính trung bình và độ dày thành nang trên $S A$ và $C L V T$. Theo phân loại Bosniak thì chủ yếu nang thận nhóm I.

\subsection{Kết quả điêuu trị}

Bảng 3.4. Thời gian phẫu thuật và tai biến, biến chứng

\begin{tabular}{|c|c|c|c|}
\hline Thời gian & $\begin{array}{c}\text { Số lượng } \\
\text { BN }\end{array}$ & Tỷ lệ & $X \pm S D$ \\
\hline$\leq 30$ phút & 2 & 4,3 & \multirow{3}{*}{$\begin{array}{c}54.74 \pm 16.60 \\
\quad(M i n-M a x \\
=30-105)\end{array}$} \\
\hline $31-60$ phút & 33 & 71,7 & \\
\hline$>60$ phút & 11 & 23,4 & \\
\hline $\begin{array}{l}\text { Tai biến và } \\
\text { biến chứng }\end{array}$ & $\begin{array}{c}\text { Số lượng } \\
\text { BN }\end{array}$ & Tỷ lệ & \\
\hline Chảy máu & 1 & 2,2 & \\
\hline $\begin{array}{c}\text { Chảy máu quâa } \\
\text { dẫn lưu }\end{array}$ & 2 & 4,3 & \\
\hline
\end{tabular}

Nhân xét: Hầu hết thời gian mổ dưới 60 phút. Tỷ lệ tai biến và biến chứng rất thấp.

Bảng 3.5. Thời gian dùng thuốc giảm đau và nằm viện sau mồ

\begin{tabular}{|c|c|c|c|c|}
\hline \multirow{2}{*}{ Thời gian } & \multicolumn{2}{|c|}{$\begin{array}{c}\text { Thời gian dùng } \\
\text { giảm đau }\end{array}$} & \multicolumn{2}{c|}{$\begin{array}{c}\text { Thời gian nằm } \\
\text { viện }\end{array}$} \\
\cline { 2 - 5 } & Số BN & Tỳ lệ & Số BN & Tỷ lệ \\
\hline 2 ngày & 19 & 41,3 & 12 & 26,1 \\
\hline 3 ngày & 21 & 45,7 & 18 & 39,1 \\
\hline 4 ngày & 6 & 13,0 & 11 & 23,9 \\
\hline
\end{tabular}

\begin{tabular}{|c|c|c|c|c|}
\hline 5 ngày & 0 & 0 & 4 & 8,7 \\
\hline 6 ngày & 0 & 0 & 1 & 2,2 \\
\hline $\begin{array}{c}\text { Trung } \\
\text { bình }\end{array}$ & $\begin{array}{c}2,72 \pm 0,69 \text { (Min- } \\
\text { Max = 2-4) }\end{array}$ & $\begin{array}{c}3,22 \pm 1,01 \text { (Min- } \\
\text { Max = 2-6) }\end{array}$ \\
\hline
\end{tabular}

Nhận xét: Phần lớn BN dùng thuốc giảm đau 2-3 ngày sau mổ, đa phần nằm viện 2-3 ngày.

\section{BÀN LUÂN}

*Tuổi và giới: Tuổi trung bình của nhóm bệnh nhân nghiên cứu là $57,72 \pm 14,84$ tuổi trong đó tuổi cao nhất là 83 và tuổi thấp nhất là 19 (Bảng 3.1). Hay gặp nhất là trên 50 tuổi chiếm 76,09\%. Kết quả nghiên cứu này tương tự với Trần Hiếu Học (2017) tuổi trung bình là 54,6 \pm 11 ,8 [3]. Đặc điểm bệnh cho thấy tuổi càng cao thì tỷ lệ mắc bệnh càng lớn, đây cũng là tuổi hay có những bệnh lý mãn tính kết hợp. Việc phâuu thuật cho những bệnh nhân này làm tăng các yếu tố nguy $\mathrm{co}$, đặt ra phẫu thuật càng giảm thiểu tổn thưong, và thời gian mổ càng ngắn càng tốt. Chính vì vạy mà áp dụng phương pháp mổ nội soi đối với bệnh lý này đáp ứng được tieu chí tren, giảm thiểu được những tai biến, biến chứng cho bênh nhân.

Tî lệ nữ/nam ngang nhau, cũng tương đồng với các nghiên cứu của Nguyễn Hoàng Đức (2005) nam chiếm $43 \%$ và nữ chiếm $57 \%$ [4] và Efesoy O. (2015), tỷ lệ nam là 54,8\%, nữ là 45,2\% [5]. Vì vậy tôi nhận thấy không có sự liên quan giữa giới tính và nguy cơ mắc bệnh.

* Đau thắt lưng: Trong nghiên cứu của chúng tôi có $40 / 46$ bẹnh nhân có triêu chứng đau thắt lưng từng đợt hoặc tức nang chiếm $86,96 \%$ trong đó có 2 trường hợp đau thắt lưng kèm theo tăng huyết áp, 2 trường hợp đau thắt lưng kèm theo chạm thận dướng tính và phát hiện khi đi khám sức khoẻ định kỳ có 6 bệnh nhân chiếm $13,04 \%$. Tỷ lệ này tương đương với nghiên cứu của Roberts WW (2011), tỷ lệ đau thắt lưng là $88 \%$ [6] và của Trân Hiêu Học (2017) là 48/56 bệnh nhân chiếm 85,7\% [3]. Đay là triẹu chứng không đặc hiệu nhưng là triệu chứng chính làm cho bệnh nhân khó chịu và đển viện khám. Triệu chứng gây khó chịu cho bênh nhân trong sinh hoạt và trong công việc hàng ngày, mức độ đau là yễu tố để lựa chọn chỉ định mổ nhằm cải thiện chất lượng cuộc sống cho bệnh nhân.

*Bệnh kèm theo: Trong nghiên cứu của chúng tôi gặp một số bệnh kết hợp như: cao huyết áp $(6,5 \%)$, đái tháo đường $(10,9 \%)$, sỏi tiết niệu (15,2\%), nang gan (6,5\%) (Bảng 3.2.) và thấy rằng hay gặp nhất là sỏi tiết niệu. Trong 3 trường hợp tăng huyết áp về suy luận thì nang 
cạnh bể thận gây chèn ép nhiều có thể dẫn tới tăng huyết áp nhưng trong nghiêu cứu này 3 trường hợp đó toàn là bệnh nền không liên quan đến bệnh nang thận. Tác giả Roberts WW (2011) nghiên cứu trên 32 bệnh nhân không gặp trường hợp nào có triệu chứng tăng huyết áp [6]. Và như vậy triệu chứng tăng huyết áp cũng không đăc hiều trong nang thân.

*Siêu âm và cắt lớp vi tính: Chúng tôi thấy không có sự khác nhau về đường kính, độ dày thành nang giữa siêu âm và chụp cắt lớp vi tính (Bảng 3.3). Đường kính nang thận trung bình trên siêu âm là $79,17 \pm 26,05 \mathrm{~mm}(45-183 \mathrm{~mm})$ và trong cắt lớp vi tính là $77,48 \pm 26,53 \mathrm{~mm}$ (45$183 \mathrm{~mm}$ ). Tỷ lệ này tương đương với nghiên cứu của Efesoy O. đường kính trung bình của nang thận là $8,5 \pm 2,7 \mathrm{~cm}$ [5]. Việc đánh giá nang thận bằng chụp cắt lớp vi tính và siêu âm không chỉ là để giúp trong việc chẩn đoán mà có thể giúp phẫu thuật viên có kế hoạch tốt hơn trong việc chọn lựa đường mổ và hướng bóc tách tìm nang thận trong lúc phẫu thuật.

*Phẩn loại nang thận theo Bosniak: Trong nghiê cứu này nang nhóm I chiếm $86,96 \%$, nhóm II chiếm 13,04\%. Kết quả này cũng tương tự kết quả của Trần Hiếu Học (2017) nang nhóm I chiếm $87,5 \%$, nhóm II chiếm 14,3\% [3] và của Trần Chí Thanh (2002) tương ứng là $85,1 \%$ và $14,9 \%$ [2]. Hiện nay phân loại nang thận theo Bosniak được sử dụng trong vấn đề đánh giá mức độ, lựa chọn phương pháp phẫu thuật, theo dôi, tiên lượng bệnh nhân. Trong nghiên cứu này, chúng tôi chỉ định điều trị phẫu thuật nội soi sau phúc mạc cho bệnh nhân nang thận theo phân loại Bosniak I, II (tiêu chuẩn đánh giá trên chụp cắt lớp vi tính).

*Thời gian phẫu thuật: Kết quả nghiên cứu cho thây thời phẫu thuật trung bình là $54,74 \pm 16,6$ phút, phần lớn $\leq 60$ phút $(76 \%)$ (Bảng 3.4.). Thời gian phẫu thuật trung bình theo nghien cứu của tác giả Lutter I (2005) là 70 phút [7]. Kết quả của chúng tôi tương đương với Nguyển Hoàng Đức (2005), thời gian phẫu thuật trung bình là 60 phút [4]. Kích thước nang thận không phải là yếu tố gây khó khăn và kéo dài cho cuộc phẫu thuật vì nang to thuờng thành nang mỏng, khi cắt ít bị chảy máu nên không mất nhiều thời gian cầm máu diẹn cắt. Trong khi với nang thận đã từng viêm truớc đó thường dính nhiều, thành dây, viec phẫu tích boc lô nang khó khăn và dễ chảy máu, nên kéo dài thời gian phẫu thuật. Trong phẫu thuật khó khăn khi phẫu tích với nang ở cực trên thạn, nen thời gian phẫu thuật lâu hon các vị trí khác.
*Tai biến trong phẫu thuật: Nghiên cứu của chúng tôi chỉ có 1 bệnh nhẩn bị chảy máu trong mổ chiếm 2,2\% (Bảng 3.4.). Tai biến này xảy ra khi cắt thành nang sâu vào nhu mô thận, lượng máu mất vào khoảng $150 \mathrm{ml}$ sau đó được phát hiện và được xử lý cầm máu kịp thời bằng ligasure và khâu mũi chũ̃ $X$ tại vị trí nhu mô thận chảy máu. Nghiên cứu của Trần Hiếu Học (2017) cũng có 1 ca chảy máu trong phẫu thuật chiếm tỷ lệ 1,8\% [3].

* Biến chứng sau phẫu thuật: chúng tôi gặp 2 trường hợp chảy máu qua dẫn luu số luợng máu mất < $100 \mathrm{ml}$. Hai trường hợp này có thể chảy máu do rỉ rả từ diện cắt nang nhưng số lượng máu mất không nhiều nên chúng tôi tiếp tục theo dõi và điều trị nội khoa thây không có chảy máu tiến triển, $2 \mathrm{BN}$ lần lượt ra viện sau 4 và 5 ngày điều trị. Chúng tôi không gặp các biến chứng khác như rò nước tiểu hay nhiễm trùng. Khác với Trần Hiếu Học (2017) có 1 trường hợp rò nước tiểu $(1,8 \%), 1$ đọng dịch $(1,8 \%)$ và 1 nhiễm trùng chân trocar $(1,8 \%)$ [3]. Qua đó cho thấy đây là một phương pháp phẫu thuật an toàn với tỷ lệ biến chứng thấp.

*Thời gian dùng thuốc giảm đau: chúng tôi đánh giá mức độ đau sau phẫu thuật theo ghi nhận của bác sĩ lâm sàng, kết quả cho thây tất cả bệnh nhân có dùng thuốc giảm đau. Thời dùng thuốc giảm đau sau phẫu thuât trung bình là $2,72 \pm 0,688$ ngày, có $86,96 \%$ BN dùng thuốc giảm đau 2-3 ngày (Bảng 3.5.). Theo nghiên cứu của Nguyễn Phú Việt, đau ít là $38,4 \%$, đau vừa là $61,5 \%$, không có trường hợp nào đau nhiêu, số ngày dùng thuốc giảm đau sau mổ trung bình $3,43 \pm 0,96$ ngày [8] và kết quả của chúng tôi cũng tương đương.

*Thời gian nằm viên sau phẫu thât: Trong nghiên cứu của chúng tôi thời gian nẳm viẹn sau phẫu thuạt trung bình là $3,22 \pm 1,01$ ngày $(\operatorname{Min}-M a x=2-6)$. Tỷ lệ bẹnh nhân nằm viẹn sau phẫu thuật 2-4 ngày là $89,1 \%$ (Bảng 3.5.). Kết quả này cũng tương đương với nghiên cứu của Lutter I (2005) thời gian nằm viện sau phẫu thuật trung bình là 3 ngày [7]. Trong nghiên cứu của chúng tôi, ngoài 2 trường hợp chảy máu qua dẫn lưu số lương máu mất $<100 \mathrm{ml}$ không ghi nhận biến chứng nào khác. Như vậy, sau phẫu thuật nội soi sau phúc mạc cắt nang thận, có thể xem xét cho bệnh nhân ra viện sớm hơn.

\section{KẾT LUẬN}

Qua 46 bệnh nhân cho thây phẫu thuật được đặt ra ở hầu hết các trường hợp có triệu chứng 
trên lâm sàng. Phẫu thuật nội soi sau phúc mạc cắt nang thận là một phương pháp xâm lấn tối thiểu an toàn, đạt hiệu quả tốt, có tính thẫm mỹ cao, ít gây đau, thời gian phục hồi sớm và có thể tiến hành thường quy tại các cơ sở có trang bị phẫu thuật nội soi.

\section{TÀI LIÊU THAM KHẢO}

1. Steven Sussman, Sachio T. Cochran, col J J P a (1984). "Hyperdense renal masses: A CT manifestation of hemorrhagic renal cysts". Radiology, 150, 207-211.

2. Trân Chí Thanh (2002). Nghiên cứu chỉ định và kết quả điêu trị Nang thận đơn thuân bằng phương pháp soi ổ bunng cắt chỏm nang. Luận văn tốt nghiệp bác sỹ nội trú, Trường Đại Học Y Hà Nội

3. Trân Hiếu Hoc, Trân Quế Sơn (2017). "Phẩu thuật nội soi cắt chỏm nang thận đơn thuân tại Bênh viện Bach Mai.". Tạp chí phẫu thuật nội soi Việt Nam.sối tập 7 , 24-30.
4. Nguyễn Hoàng Đức, Nguyễn Hoàng Bắc, Trân Lê Linh Phương (2005). "Phương pháp cắt chỏm nang thận nội soi sau phúc mạc và qua phúc mạc". Tap chí YY học tp Hồ Chí Minh, Phụ bản số 1, Tập 9

5. Efesoy 0, Tek M, Bozlu M, et al (2015). "Comparison of single-session aspiration and ethanol sclerotherapy with laparoscopic de-roofing in the management of symptomatic simple renal cysts". Turk J Urol, 41 (1), 14-19.

6. Wiliam W. Roberts R B L, Karen E. Boyle and col. (2001). "Laparoscopic ablation of symptomatic parenchymal and peripelvic renal cysts". Urology, 58 , 165-169.

7. Lutter I, Weibl P, Daniel I, et al (2005). "Retroperitoneoscopic approach in the treatment of symptomatic renal cysts". Bratisl Lek Listy, 106, $366-370$.

8. Nguyê̂n Phú Viêt, Lê Anh Tuấn, Dương Xuân Hòa, Phạm Duy Hùng (2009) "Điều trị cắt chỏm nang đơn thân bằng phẩu thuât nội soi sau phúc mạc. 40 trường hợp". Tap chí $Y$ dược học quân sự,' số 8, tr 1-14.

\section{ĐẶC ĐIỂM LÂM SÀNG VIÊM LỢI VÀ MộT Số YẾU TỐ LIÊN QUAN TRÊN BỆNH NHÂN ĐEO MẮC CÀI CHİNH NHA}

\section{TÓM TẮT}

Mục tiêu: nghiên cứu tình trạng viêm lợi và một số yếu tố liên quan trên bênh nhân đeo mắc cài chỉnh nha. Đối tượng và phướng pháp: nghiên cứu được thực hiện trên 62 bệnh nhân đeo mắc cài có tình trang viềm lợi cần điều trị. Các đối tượng được khám lâm sàng để đánh giá chỉ số lợi (GI) và chỉ số mảng bám (PLI). Sử dụng thống kê y học để phân tích các kết quả nghiên cứu được. Kết quả: Không có sự khác biệt có ý nghĩa về giá trị trung bình (GTTB) các chỉ số theo giới và thời gian đeo mắc cài. Chỉ số GI ở nhóm BN dưới 18 tuổi cao hơn nhóm từ 18 tuổi trở lên, ở nhóm lấy cao răng trước đó trên 12 tháng cao hơn ở nhóm được lấy cao răng trong khoảng thời gian 6-12 tháng trước nghiên cứu $(p<0,05)$. Chỉ số GI và PLI cao nhất ở nhóm chải răng 1 lần/ngày, thấp hơn ở nhóm chải răng 2 lần/ngày và thấp nhất ở nhóm chải răng 3 lần/ngày, ở nhóm không có thói quen dùng các biện pháp hố trợ làm sạch răng cao hơn có ý nghĩa so với nhóm có dùng ít nhất 1 biện pháp hỗ trợ làm sạch răng $(p<0,05)$. Kết luận: Không có sự khác biệt về tình trang viêm lợi giữa nam và nữ. Mức đô viêm lợi ở lứa tuổi dưới 18 nặng hơn so với lứa tuổi trên 18. Tình trang viêm lợi có liên quan đến số lần chải răng trong ngày, thói quen dùng các biện pháp hỗ trợ làm sạch răng, khoảng thời gian lây cao răng định kỳ gần nhất,

*Bệnh viên RHM TU, Hà Nội

Chịu trách nhiệm chính: Ngỗ Thùy Linh

Email: linhngo.dds@gmail.com

Ngày nhận bài: 6/7/2021

Ngày phản biên khoa học: 1/8/2021

Ngày duyệt bài: 25/8/2021

\section{Ngô Thùy Linh*, Nguyễn Thị Hồng Minh* \\ nhưng không liên quan đến thời gian đeo mắc cài. \\ Tư khóa: Viêm lợi, mắc cài chỉnh nha \\ SUMMARY \\ CLINICAL CHARACTERISTICS OF GINGIVITIS AND SOME RELATED FACTORS IN PATIENTS WEARING ORTHODONTIC BRACES}

Objectives: To studygingivitis statusand some related factors in patients wearing orthodontic braces. Subjects and research methods: The study was conducted on 62 patients wearing braces with gingivitis requiring treatment. All patients were clinically examined for gingival index (GI) and plaque index (PLI). The result was analized by medical statistic software. Results: There was no significant difference in the mean value of indicators by gender and time of wearing braces. The GIindex of under 18 year -old group was higher than that of over 18 yearold group. The group of previous calculus removal over 12 months had GI index higher than group having calculus removed during $6-12$ months before the study $(p<0,05)$. The GI and PLI indexes were highest in the group brushing teeth once a day, lower in the group brushing twice a day, and lowest in the group brushing three times a day. These indexes of the group that did not have the habit of using supportive measures teeth cleaning was significantly higher than the group using at least 1 dental cleaning support $(p<0,05)$. Conclusion: There is no difference of gingival status between men and women. The gingivitis level of under 18 year -old group wasmore severe than that of over 18 year-old group. The gingivitis status was related to the brushing times a 